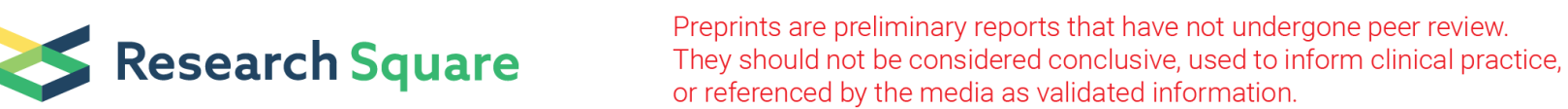

\title{
Metreleptin as A Rescue Therapy in A Patient With A Novel Mutation for Familial Partial Lipodystrophy Type 3, Originally Presenting as Type 1 Diabetes.
}

\section{VAIA LAMBADIARI ( $\nabla$ vlambad@otenet.gr)}

General University Hospital of Athens Attikon: Panepistemiako Geniko Nosokomeio Attikon

\section{AIKATERINI KOUNTOURI}

General University Hospital Attikon

\section{EIRINI MARATOU}

General University Hospital of Athens Attikon: Panepistemiako Geniko Nosokomeio Attikon

\section{STAVROS LIATIS}

Laiko General Hospital: Laiko Geniko Nosokomeio Athenon

\section{GEORGE DIMITRIADIS}

National and Kapodistrian University of Athens Faculty of Medicine: Ethniko kai Kapodistriako Panepistemio Athenon latrike Schole

\section{FREDRIK KARPE}

Oxford Radcliffe Hospitals NHS Trust: Oxford University Hospitals NHS Foundation Trust

\section{Case Report}

Keywords: Diabetes mellitus, Hypertriglyceridemia, Metreleptin, Familial partial lipodystrophy, PPARG, Insulin Resistance

Posted Date: January 28th, 2021

DOl: https://doi.org/10.21203/rs.3.rs-154503/v1

License: (c) (1) This work is licensed under a Creative Commons Attribution 4.0 International License. Read Full License 


\section{Abstract}

Background: Familial partial lipodystrophy type 3 (FPLD3) is a very rare autosomal dominant genetic disorder which is caused by mutations in the peroxisome proliferator activated receptor gamma (PPARG) gene. It is characterized by a partial loss of adipose tissue leading to subnormal leptin secretion and metabolic complications. Metreleptin, a synthetic analogue of human leptin, is an effective treatment for generalized lipodystrophies, but the evidence for efficacy in patients with FPLD3 is scarce.

Case presentation: We present a 61-year-old woman, initially misdiagnosed as type 1 diabetes since the age of 29, with severe insulin resistance, who gradually displayed a more generalized form of lipoatrophy and extreme hypertriglyceridemia, hypertension and multiple manifestations of cardiovascular disease. She was found to carry a novel mutation leading to PPARG ${ }_{\text {Glu1 } 157 G l y}$ variant. After six months of metreleptin treatment $\mathrm{HbA} 1 \mathrm{c}$ decreased from $10 \%$ to $7.9 \%$ and fasting plasma triglycerides were dramatically reduced from $2.919 \mathrm{mg} / \mathrm{dl}$ to $198 \mathrm{mg} / \mathrm{dl}$.

Conclusions: This case highlights the importance of early recognition of FPLD syndromes otherwise frequently observed as a difficult-to-classify and manage diabetes cases, in order to prevent cardiovascular complications. Metreleptin may be an effective treatment for FPLD3.

\section{Background}

Lipodystrophies constitute a rare group of heterogenous genetic or acquired disorders which mainly characterized by partial or total loss of adipose tissue. Most often they are associated with cardiometabolic abnormalities including insulin resistance, diabetes mellitus, hypertriglyceridemia, nonalcoholic fatty liver disease, features of polycystic ovary syndrome (hirsutism, oligomenorrhoea, polycystic ovaries) and premature cardiovascular disease. Lipodystrophies are classified into partial or generalized depending on the extent of fat loss. Further mechanistic classification can rely on genetic analysis using specific target genes for congenital generalized lipodystrophy or familial partial lipodystrophy $[1,2]$.

Familial partial lipodystrophy type 3 (FPLD3) is a rare type of lipodystrophy and results from mutations in the PPARGgene. FPLD3 is characterized by partial subcutaneous fat loss from upper and lower extremities, with preserved fat in the face, neck and truncal region [3]. However, although the fat mass in the abdominal compartment is preserved, this may not necessarily mean the function of the tissue is normal [4].It is believed that the aberrant function of the subcutaneous fat depots is the underlying cause of ectopic fat deposition in liver and muscle. Patients with FPLD3 usually present with metabolic disorders including diabetes mellitus, severe hypertriglyceridemia, subnormal leptin concentrations and signs of insulin resistance (acanthosis nigricans) [3,5].

Metreleptin, a synthetic analogue of human leptin that binds to and activates leptin receptor was firstly approved by FDA in 2014 for generalized lipodystrophies [6]. Since then a number of studies have shown that metreleptin is an effective treatment for partial lipodystrophies $[7,8]$. However, the evidence for 
efficacy of metreleptin in patients with FPLD3 are scarce $[9,10]$. We are here presenting an FPLD3 successfully managed with metreleptin. A written informed consent for publication was obtained from the patient.

\section{Case Presentation}

This is a 61-year-old woman who presented with diabetic symptoms and misclassified as having type 1 diabetes with negative autoimmune-related type 1 diabetes antibodies: Tyrosine Phosphatase antibobies:0.3 U/ml (negative < 10) and Glutamic acid Decarboxylase antibodies:0.5 U/ml (negative< 10). She was referred to our center due to uncontrolled diabetes despite the high doses of insulin and the coexistence of severe insulin resistance and decreased body mass index (BMl:19.4 kg/m²). Age of presentation was 29 years and for the following 30 years she was treated with multiple daily insulin injections with high insulin requirements $(5 \mathrm{lU} / \mathrm{kg} /$ day) together with metformin $2 \mathrm{gr} /$ day for 30 years, but constantly displaying poor glycemic control. Dyslipidemia was observed at the age of 35 years with raised cholesterol levels and severe hypertriglyceridemia despite intense lipid lowering therapy which lately consisted of the combination of fenofibrate $145 \mathrm{mg}$, rosuvastatin $40 \mathrm{mg} /$ day and omega- 3 fatty acids/day together with restricted fat intake. Hypertension was observed at the age of 5 years, and lately treated with the combination of nifedipine $120 \mathrm{mg} /$ day, eplerenone $25 \mathrm{mg} /$ day and hydrochlorothiazide $25 \mathrm{mg} /$ day.

She also had micro- and macrovascular complication of diabetes indicating constantly insufficient glycemic control. She presented peripheral diabetic neuropathy, and nephropathy (eGFR: $43 \mathrm{ml} / \mathrm{min}$, albuminuria: $314 \mathrm{mg} / 24 \mathrm{~h}$ ). She also suffered from severe cardiovascular disease including peripheral artery disease, and hypertrophic myocardiopathy. Peripheral artery disease presented as intermittent claudication and carotid stenosis, for which she had a right carotid endarterectomy at the age of 52 years old. She was managed with clopidogrel $75 \mathrm{mg} /$ day.

She had menarche at age 11, followed by irregular menstruation and then premature menopause at the age of 38. She also reported polycystic ovarian syndrome and never conceived. She underwent hysterectomy due to fibroids at the age of 54 . She was diagnosed with osteoporosis at the age of 58 and has since received alendronate $70 \mathrm{mg} /$ week.

\section{Family History}

It has not been possible to conduct genetic family screening. Her mother and her maternal aunt have diabetes from a young age, and both showed early presentation of cardiovascular disease, presenting as ischemic stroke at the age of 45 years old and myocardial infarction at the same age, respectively. Her mother had reproductive problems and six miscarriages. Two out of four sisters and one brother developed hypertension and dyslipidemia in young age.

\section{Genetic Analysis}


A genetic screening for lipodystrophy revealed a novel heterozygous mutation in the PPARG gene (c470A $>$ G, p. Glu157Gly, exon3). (The University of Chicago Genetic Services Laboratory). This particular amino acid change has not been described in other patients with PPARG-related disorders, but a different pathogenic sequence change affecting the same amino acid residue ( $p$. Glu157Asp) has been described in a family with PPARG-related lipodystrophy [11].

\section{Examination}

Examination revealed clinical signs of lipodystrophy of upper and lower limbs and gluteal area. Facial fat and abdominal prominence were also noted. She also had phlebectasia, hirsutism and cervical acanthosis nigricans. The patient mentioned that this phenotype was present from a young age. Blood pressure was 175/84 mmHg.She was underweighted with a BMl: $19.40 \mathrm{~kg} / \mathrm{m}^{2}$ (weight: $46 \mathrm{~kg}$, height:154 cm). Muscle weakness, presenting with a weak hand grip and exercise intolerance with pain and frailty were also prominent (Fig. 1A).

To assess the degree of regional fat loss in this case, we compared the total and proportional fat content in defined body regions using Dual-energy x-ray absorptiometry (DXA) with a group of healthy, lean postmenopausal women [12]. The case has a relatively short stature and as a consequence a total lean mass not far from the lower end the $95 \%$ confidence interval of the comparators. The total fat mass was drastically lower giving a first indication of a lipodystrophic state. The visceral fat mass was similar to the comparators whilst the proportional fat content in extremities was drastically reduced showing the classic features of peripheral fat loss in partial lipodystrophy (Table 1). 
Table 1

Regional body fat content in the case

\begin{tabular}{|c|c|c|}
\hline & Case & $\begin{array}{l}\text { Healthy comparator group } \\
n=13\end{array}$ \\
\hline Age (years) & 64 & $59(58-60)$ \\
\hline BMI $\left(\mathrm{kg} / \mathrm{m}^{2}\right)$ & 19.7 & $23.1(22.7-23.5)$ \\
\hline Height (cm) & 153 & $161(159-162)$ \\
\hline Total fat mass $(\mathbf{k g})$ & 10.9 & $20.1(19.2-21.1)$ \\
\hline Total Lean mass (kg) & 34.1 & $36.6(35.5-37.6)$ \\
\hline Android subcutaneous fat mass (kg) & 0.6 & $1.0(0.9-1.1)$ \\
\hline Android visceral fat mass $(\mathrm{kg})$ & 0.3 & $0.3(0.2-0.4)$ \\
\hline Gynoid fat mass $(\mathrm{kg})$ & 1.3 & $4.0(3.8-4.2)$ \\
\hline Arm fat\% & 26.5 & $40(38-41)$ \\
\hline Leg fat \% & 18.7 & $40(38-41)$ \\
\hline Comparator values are mean $(95 \% \mathrm{cc}$ & fidence & nterval) \\
\hline
\end{tabular}

\section{Biochemical Measurements}

At the time of the first evaluation biochemical measurements revealed glycated hemoglobin (HbA1C) of $10 \%$, total cholesterol of $132 \mathrm{mg} / \mathrm{dl}$ of which high density lipoprotein (HDL-C) was $25 \mathrm{mg} / \mathrm{dl}$. There was severe hypertriglyceridemia at $2,919 \mathrm{mg} / \mathrm{dl}$. Further tests confirmed chronic kidney disease (blood urea nitrogen:49.6 mg/dl, creatinine: $1.3 \mathrm{mg} / \mathrm{dl}$, eGFR: $43 \mathrm{ml} / \mathrm{min}$ ) and albuminuria (314 mg/24 h).

We performed glucagon stimulation test which revealed residual insulin secretion (fastingCpeptide:2.09 ng/ml, 6 minutes after $1 \mathrm{mg}$ of glucagon infusionC-peptide:3.13 ng/ml). Plasma leptin concentration was close to zero $(0.43 \mathrm{ng} / \mathrm{ml})$.

\section{Imaging Assessment}

Abdominal ultrasound confirmed hepatic steatosis and transient elastography (fibroscan) detected liver stiffness of $18 \mathrm{Kpa}$.Abdominal Magnetic Resonance Imaging (MRI) was unremarkable apart from hepatomegaly with a liver percentage fat fraction of 9.4\%, and an enlarged spleen (Fig. 1D). Cardiac MRI revealed left ventricular hypertrophy (maximal wall thickness $17 \mathrm{~mm}$ ) and myocardial fibrosis in the basal interventricular septum (LGE SCORE 1/48, LGE mass $2 \%$ ). Two-dimensional echocardiography revealed severe left ventricular hypertrophy, minimal mitral regurgitation, and ejection fraction of $60 \%$ (Fig. 1B).

\section{Effect of metreleptin treatment}


After noting her poor glycemic control, her antidiabetic treatment was intensified with empagliflozin $10 \mathrm{mg} /$ daily and liraglutide $1.8 \mathrm{mg} /$ daily, but this resulted only in a slight improvement in glycemic control after 3 months (HbA1c: 9.3\%), despite additional strict dietetic management, but without any change in insulin management. We did not observe any change in triglyceride (TG) levels.

Metreleptin was then initiated at $5.8 \mathrm{mg}$ once daily on top of the current lipid and diabetes management. Glycemic control and hypertriglyceridemia improved within two months of treatment evidenced by decrease of $\mathrm{HbA} 1 \mathrm{C}$ from $10-8.7 \%$ and the reduction of TG from a baseline value of $2919 \mathrm{mg} / \mathrm{dl}$ to $242 \mathrm{mg} / \mathrm{dl}$. At six months there was further reduction in HbA1C (7.9\%) and in TG (198 mg/dl). This improvement was sustained one year after treatment with metreleptin in same dose ( $\mathrm{HbA} 1 \mathrm{C}: 8 \%$, TG:185 mg/dl-standard serum determinations are listed in Table 2). Insulin doses were reduced from more than $5 \mathrm{IU} / \mathrm{kg} /$ day to $2.22 \mathrm{lU} / \mathrm{kg} /$ day. Blood pressure was also better controlled without any change in anti-hypertensive medication.

Table 2

Summary of the results over 12 months of metreleptin therapy

\begin{tabular}{|lllll|}
\hline & Baseline & 2 months & 6 months & 12 months \\
\hline HbA1C (\%) & 10 & 8.7 & 7.9 & 8 \\
\hline TG (mg/dl) & 2919 & 242 & 198 & 185 \\
\hline Total cholesterol (mg/dl) & 132 & 137 & 115 & 106 \\
\hline HDL (mg/dl) & 25 & 25 & 26 & 29 \\
\hline LDL (mg/dl) & - & 64 & 49 & 46 \\
\hline ALT (mg/dl) & 24 & 24 & 18 & 17 \\
\hline AST (mg/dl) & 21 & 27 & 24 & 26 \\
\hline BUN (mg/dl) & 49.6 & 56 & 25 & 39 \\
\hline Creatinine (mg/dl) & 1.3 & 1.3 & 1.04 & 1.09 \\
\hline Liver fat fraction (\%) & 9.4 & - & 6.8 & - \\
\hline $\begin{array}{l}\text { Liver Stiffness (Kpa) } \\
\text { BMI (Kg/m }{ }^{2} \text { ) }\end{array}$ & 18 & - & 18 & 18.98 \\
\hline $\begin{array}{l}\text { ALT: alanine aminotransferase, AST: aspartate transaminase, BMl: Body Mass Index, BUN: blood urea } \\
\text { nitrogen, HbA1C: glycated hemoglobin, HDL: high-density lipoprotein, LDL: low-density lipoprotein, TG: } \\
\text { triglycerides. The biochemical assessment was performed after 8 hours fasting. }\end{array}$ \\
\hline
\end{tabular}

At six months of metreleptin treatment a reduced liver fat content was observed (MRI estimated liver percentage fat fraction was reduced from 9.4-6.8\%). However, liver stiffness assessed by transient elastography remained stable. A repeated DXA scan showed unchanged total fat mass content and 
cardiac MRI revealed no change (Fig. 1C). Reduction in appetite following metreleptin treatment was reported. Metreleptin treatment was well tolerated with no other adverse effects.

\section{Discussion And Conclusions}

We present the case of a patient misdiagnosed as having poorly controlled type 1 diabetes for more than 30 years but finally identified as having FPLD3 with typical body clinical features and unusually low serum leptin concentration. Conventional and intensified antidiabetic treatment failed to normalize glycemic control but the introduction of metreleptin resulted in a drastic improvement of glycemic control and plasma triglycerides. Uncontrolled diabetes despite the high doses of insulin in conjunction with decreased body mass index and signs of insulin resistance should be red flags for the clinician to redefine the type of diabetes towards the possibility of lipodystophy. Furthermore, the suspicion is enhanced by the coexistence of negative antibodies testing and residual insulin secretion in glucagon stimulation test. So far, only ten cases of patients with FPLD3 receiving metreleptin are reported in the literature $[9,10,13]$. While metreleptin seems to improve glycemic control, its efficacy regarding hypertriglyceridemia in these group of patients is questionable. The degree of leptin deficiency and the severity of metabolic derangement may predict the efficacy of metreleptin in other forms of partial lipodystrophy $[14,15]$ which fits with this case of FPLD3. The case should: 1) raise awareness to clinicians of the diagnosis of lipodystrophy in patients with severe metabolic disorders despite intensified metabolic treatment and 2) affirm that patients with FPLD3 may benefit from metreleptin treatment, and 3) once again challenge the entity of difficult-to-manage diabetes patients.

\section{Abbreviations}

BMI Body mass index

DXA Dual-energy $x$-ray absorptiometry

eGFR Estimated Glomerular Filtration Rate

FPLD3 Familial partial lipodystrophy type 3

HbA1C Glycated hemoglobin

HDL High density lipoprotein

LGE Late gadolinium enhancement

MRI Magnetic Resonance Imaging

PPARG Peroxisome proliferator activated receptor gamma

TG Triglycerides 


\section{Declarations}

Ethics Approval and consent to participate: Not applicable

Consent for publication: A written informed consent for publication was obtained.

Availability of data and materials: Data sharing is not applicable to this article as no datasets were generated or analyzed during the current study.

Competing Interests: The authors declare that they have no competing interests.

Funding: No funding was received for this study

Authors contributions: All authors have made a substantial contribution to the work and approved it for publication, with Associate Professor Vaia Lambadiari being the guarantor for the contents of the article. V.L., S.L were responsible for the diagnosis and treatment of the patient. A.K., EM, G.D., were responsible for the data collection and the search of the bibliography. V.L and F. K wrote and edited the manuscript. All the authors approved the final version of the manuscript.

Acknowledgements: Not applicable

\section{References}

1. Garg A. Clinical review\#: Lipodystrophies: genetic and acquired body fat disorders. J Clin Endocrinol Metab. 2011 Nov;96(11):3313-25.

2. Garg A. Acquired and inherited lipodystrophies. N Engl J Med. 2004 Mar;18(12):1220-34. 350(.

3. Agarwal AK, Garg A. A novel heterozygous mutation in peroxisome proliferator-activated receptorgamma gene in a patient with familial partial lipodystrophy. J Clin Endocrinol Metab. 2002 Jan;87(1):408-11.

4. Tan GD, Savage DB, Fielding BA, Collins J, Hodson L, Humphreys SM, O'Rahilly S, Chatterjee K, Frayn $\mathrm{KN}$, Karpe F. Fatty acid metabolism in patients with PPARgamma mutations. J Clin Endocrinol Metab. 2008;93(11):4462-70.

5. Savage DB, Tan GD, Acerini CL, Jebb SA, Agostini M, Gurnell M, Williams RL, Umpleby AM, Thomas EL, Bell JD, Dixon AK, Dunne F, Boiani R, Cinti S, Vidal-Puig A, Karpe F, Chatterjee VK, O'Rahilly S. Human metabolic syndrome resulting from dominant-negative mutations in the nuclear receptor peroxisome proliferator -activated receptor-gamma. Diabetes. 2003;52(4):910-7.

6. MYALEPT (metreleptin). US prescribing information. Boston: Aegerion Pharmaceuticals, Inc.; 2015.

7. Rodriguez AJ, Mastronardi CA, Paz-Filho GJ. New advances in the treatment of generalized lipodystrophy: role of metreleptin. Ther Clin Risk Manag. 2015 Sep;16:11:1391-400.

8. Oral EA, Simha V, Ruiz E, Andewelt A, Premkumar A, Snell P, Wagner AJ, DePaoli AM, Reitman ML, Taylor SI, Gorden P, Garg A. Leptin-replacement therapy for lipodystrophy. N Engl J Med. 2002 Feb 
21;346(8):570-8.

9. Chong AY, Lupsa BC, Cochran EK, Gorden P. Efficacy of leptin therapy in the different forms of human lipodystrophy. Diabetologia. 2010 Jan;53(1):27-35.

10. Guettier JM, Park JY, Cochran EK, Poitou C, Basdevant A, Meier M, Clément K, Magré J, Gorden P. Leptin therapy for partial lipodystrophy linked to a PPAR-gamma mutation. Clin Endocrinol (Oxf). 2008 Apr;68(4):547-554.

11. Campeau PM, Astapova O, Martins R, Bergeron J, Couture P, Hegele RA, Leff T, Gagné C. Clinical and molecular characterization of a severe form of partial lipodystrophy expanding the phenotype of PPARy deficiency. J Lipid Res. 2012;53(9):1968-78.

12. Hodson L, Banerjee R, Rial B, Arlt W, Adiels M, Boren J, Marinou K, Fisher C, Mostad IL, Stratton IM, Barrett PH, Chan DC, Watts GF, Harnden K, Karpe F, Fielding BA. Menopausal Status and Abdominal Obesity Are Significant Determinants of Hepatic Lipid Metabolism in Women. J Am Heart Assoc. 2015 Oct 2;4(10):e002258.

13. Sekizkardes H, Cochran E, Malandrino N, Garg A, Brown RJ. Efficacy of Metreleptin Treatment in Familial Partial Lipodystrophy Due to PPARG vs LMNA Pathogenic Variants. J Clin Endocrinol Metab. 2019 Aug 1;104(8):3068-3076.

14. Brown RJ, Araujo-Vilar D, Cheung PT, Dunger D, Garg A, Jack M, Mungai L, Oral EA, Patni N, Rother KI, von Schnurbein J, Sorkina E, Stanley T, Vigouroux C, Wabitsch M, Williams R, Yorifuji T. The Diagnosis and Management of Lipodystrophy Syndromes: A Multi-Society Practice Guideline. J Clin Endocrinol Metab. 2016 Dec;101(12):4500-11.

15. Diker-Cohen T, Cochran E, Gorden P, Brown RJ. Partial and generalized lipodystrophy: comparison of baseline characteristics and response to metreleptin. J Clin Endocrinol Metab. 2015 May;100(5):1802-10.

\section{Figures}


A

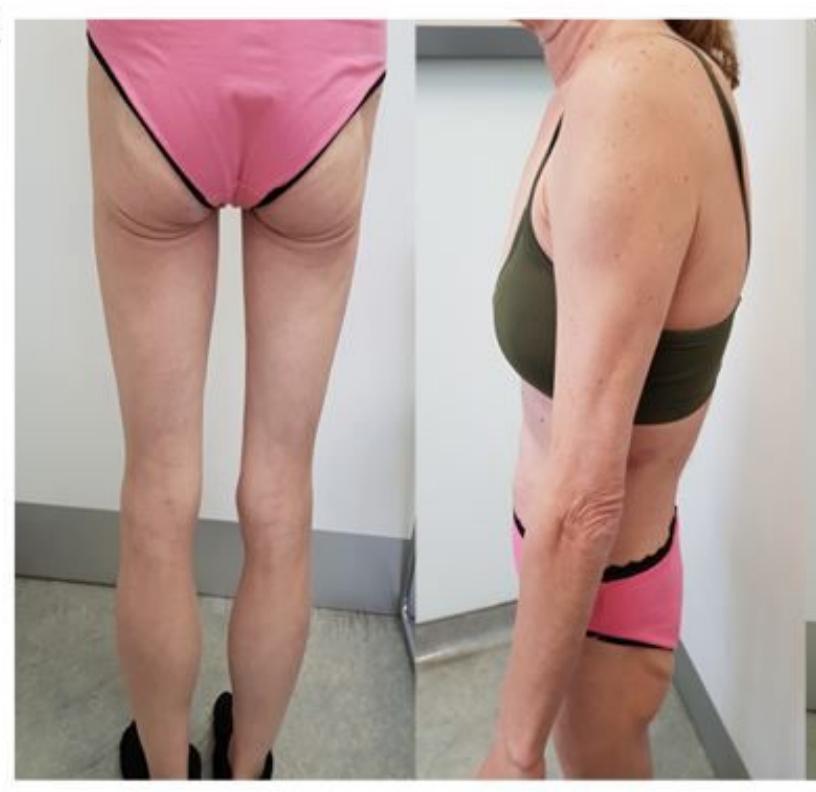

C

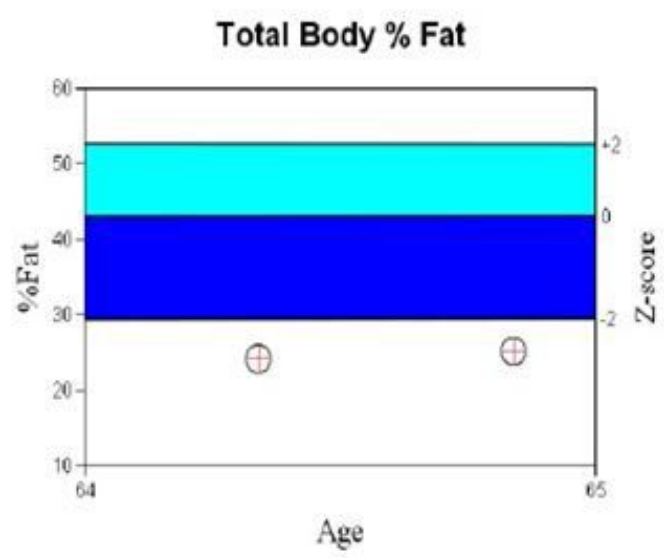

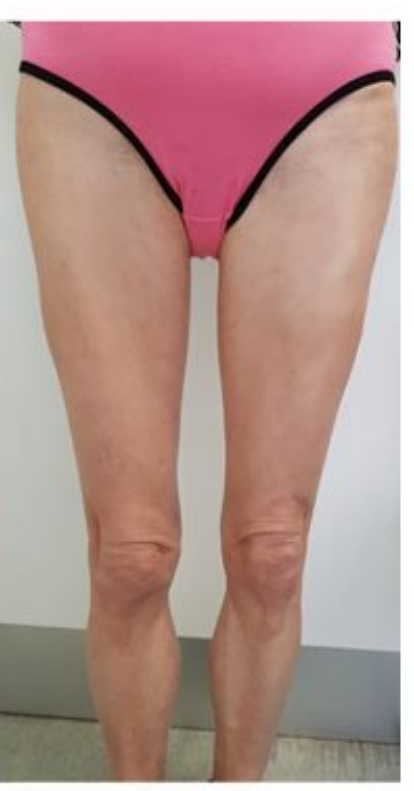

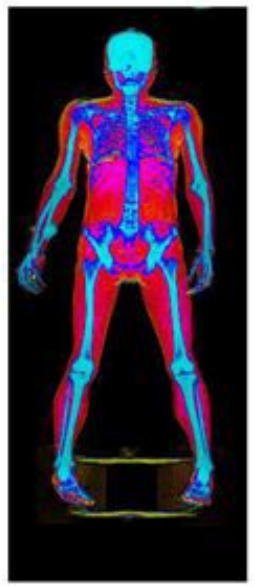

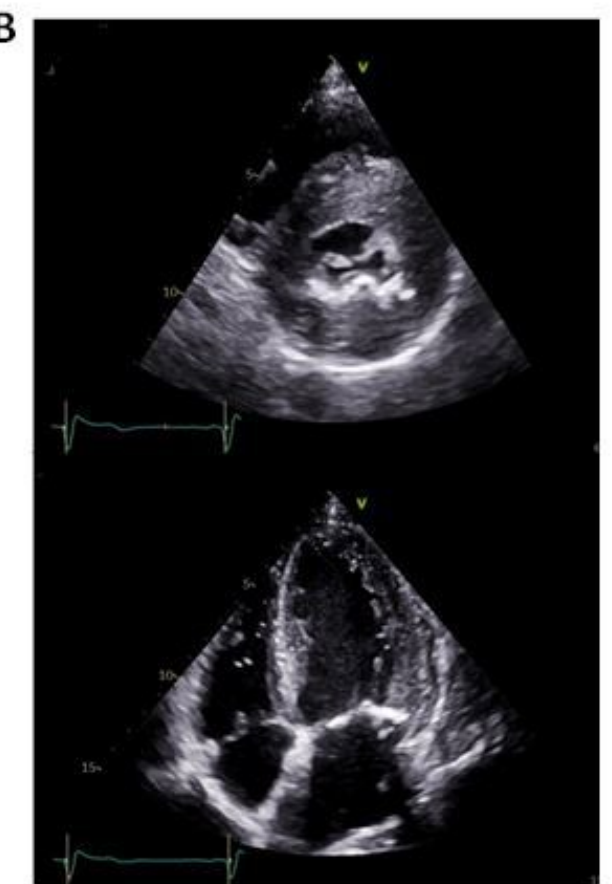

D

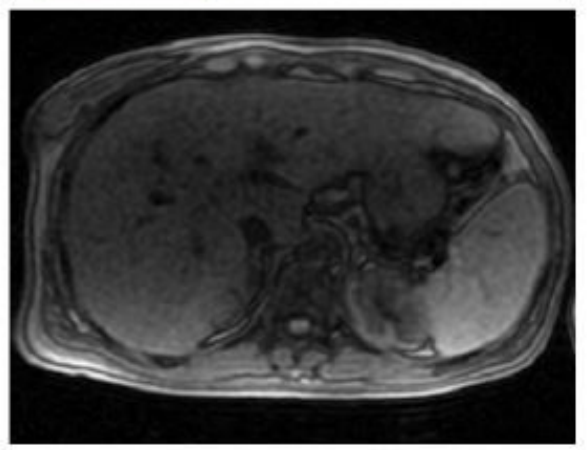

\section{Figure 1}

A: Total lipoatrophy of extremities and gluteal area, B: Two dimensional echocardiography revealed left ventricular hypertrophy (interventricular septum thickness $20 \mathrm{~mm}$ ), C: DXA showed increased fat tissue of the abdominal region and decreased fat mass of the upper and lower limbs. Follow- up DXA indicated unchanged total fat mass content, D: The abdominal MRI image shows hepatic steatosis

\section{Supplementary Files}

This is a list of supplementary files associated with this preprint. Click to download.

- CAREchecklist.pdf 